\title{
Sodium-hydrogen exchanger NHA1 and NHA2 control sperm motility and male fertility
}

\author{
Su-Ren Chen ${ }^{\star, 1}$, M Chen ${ }^{1}$, S-L Deng ${ }^{1}$, X-X Hao ${ }^{1,2}$, X-X Wang ${ }^{1}$ and Y-X Liu*,1
}

Our previous work identified NHA1, a testis-specific sodium-hydrogen exchanger, is specifically localized on the principal piece of mouse sperm flagellum. Our subsequent study suggested that the number of newborns and fertility rate of NHA1-vaccinated female mice are significantly stepped down. In order to define the physiological function of NHA1 in spermatozoa, we generated Nha1 ${ }^{\mathrm{F} \times / F \mathrm{x}}, \mathrm{Zp3}$-Cre (hereafter called Nha1 $\mathrm{cKO}$ ) mice and found that Nha1 $\mathrm{cKO}$ males were viable and subfertile with reduced sperm motility. Notably, cyclic AMP (cAMP) synthesis by soluble adenylyl cyclase (sAC) was attenuated in Nha1 cKO spermatozoa and cAMP analogs restored sperm motility. Similar to Nha1 cKO males, Nha2 ${ }^{\mathrm{Fx} / \mathrm{Fx}}, \mathrm{Zp3}-\mathrm{Cre}$ (hereafter called Nha2 cKO) male mice were subfertile, indicating these two Nha genes may be functionally redundant. Furthermore, we demonstrated that male mice lacking Nha1 and Nha2 genes (hereafter called Nha1/2 dKO mice) were completely infertile, with severely diminished sperm motility owing to attenuated SAC-cAMP signaling. Importantly, principal piece distribution of NHA1 in spermatozoa are phylogenetically conserved in spermatogenesis. Collectively, our data revealed that NHA1 and NHA2 function as a key sodium-hydrogen exchanger responsible for sperm motility after leaving the cauda epididymidis.

Cell Death and Disease (2016) 7, e2152; doi:10.1038/cddis.2016.65; published online 24 March 2016

As many as $15 \%$ of human couples are infertile, and male infertility is about half of these cases. ${ }^{1}$ To fertilized egg, spermatozoa from the cauda epididymis must travel a long journey in the female reproductive tract to reach ampulla of uterine tube. Interestingly, in most mammalian species examined, the sperm journey experiences a natural increase in $\mathrm{Na}^{+} / \mathrm{HCO}_{3}^{-}$concentration and $\mathrm{pH}$ value $(\mathrm{pH}<7$, $\mathrm{Na}^{+}<25 \mathrm{mM}, \mathrm{HCO}_{3}^{-}<1 \mathrm{mM}$ in cauda epididymis, whereas $\mathrm{pH} \sim 7.4, \mathrm{Na}^{+}>100 \mathrm{mM}, \mathrm{HCO}_{3}^{-}>10 \mathrm{mM}$ in female reproductive tract). ${ }^{2,3}$ It is thus clear that intracellular $\mathrm{pH}(\mathrm{pHi})$ regulation is of the utmost importance for sperm physiology, including motility, maturation and the acrosome reaction. ${ }^{4}$ The maintenance of sperm $\mathrm{pHi}$ is kept through the involvement of several mechanisms, among which is included the sodium $\left(\mathrm{Na}^{+}\right)$-hydrogen $\left(\mathrm{H}^{+}\right)$exchangers (NHEs). ${ }^{5}$

NHEs, also known as $\mathrm{Na}^{+} / \mathrm{H}^{+}$antiporters (NHAs), are integral membrane proteins that catalyze the exchange of $\mathrm{Na}^{+}$ for $\mathrm{H}^{+}$across lipid bilayers and are ubiquitously distributed in almost all living organisms. ${ }^{6}$ The SLC9 gene family encodes NHEs and can be divided into three subgroups (reviewed in Martins et al. ${ }^{7}$ ). The SLC9A subgroup encompasses plasmalemmal isoforms NHE1-5 (SLC9A1-5) and the predominantly intracellular isoforms NHE6-9 (SLC9A6-9). The SLC9B subgroup consists of two recently cloned isoforms, NHA1 and NHA2 (SLC9B1 and SLC9B2, also known as NHEDC1 and NHEDC2). The SLC9C subgroup consist of a spermspecific plasmalemmal NHE (SLC9C1, also known as sNHE) and a putative NHE, SLC9C2, for which there is currently no functional data.

Four $\mathrm{Na}^{+} / \mathrm{H}^{+}$exchangers (NHE1, ${ }^{8} \mathrm{NHE} 5,{ }^{9} \mathrm{sNHE}^{10}$ and $\mathrm{NHA} 1^{11}$ ) are reported to be expressed in spermatozoa. However, normal sperm motility is maintained in Nhe1-null mice, suggesting that Nhe1 gene is male fertility independent. ${ }^{12}$ Testis histology, sperm numbers and morphology are normal, but $s$ Nhe null males are completely infertile with severely diminished sperm motility. ${ }^{10}$ Further study suggests that cyclic AMP (cAMP) metabolism is impaired in spermatozoa lacking SNHE. ${ }^{13}$ A recent study showed that NHE8 is highly expressed in the Leydig cells and male mice lacking Nhe8 gene are infertile through its effect on modifying luteinizing hormone receptor (LHR) function. ${ }^{14}$

Second messenger cAMP has been reported to be essential for sperm function, including activation of motility, hyperactivation and acrosome reaction, mainly via activation of holoenzyme protein kinase $A(P K A) .{ }^{15}$ In mammalian spermatozoa, cAMP is synthesized by a soluble isoform of the adenylyl cyclase (sAC) family. ${ }^{16,17}$ There are two alternative splicing products, which independently encode full-length $\mathrm{SAC}$ $\left(\mathrm{sAC}_{\mathrm{fl}}\right)$ and truncated forms of $\mathrm{sAC}\left(\mathrm{sAC}_{\mathrm{t}}\right) .{ }^{18} \mathrm{~s} A C$-null male mice are infertile because of a severe defect in sperm motility. ${ }^{19,20}$ In addition, as $\mathrm{HCO}_{3}^{-}$directly regulates $\mathrm{SAC}$, this enzyme is able to translate $\mathrm{pH}$ changes into cAMP levels. ${ }^{21,22}$

The sperm flagellum-specific NHE identified by Liu et al. ${ }^{23}$ in our laboratory in 2010 is now classified into a new family of

\footnotetext{
${ }^{1}$ State Key Laboratory of Stem Cell and Reproductive Biology, Institute of Zoology, Chinese Academy of Sciences, Beijing, China and ${ }^{2}$ University of Chinese Academy of Sciences, Beijing, China

*Corresponding author: S-R Chen or Y-X Liu, State Key Laboratory of Stem Cell and Reproductive Biology, Institute of Zoology, Chinese Academy of Sciences, 1 Beichen West Road, Chaoyang District, Beijing 100101, China. Tel: +86 10 64807038; Fax: +86 10 64807058; E-mail: chensuren@ioz.ac.cn or liuyx@ioz.ac.cn

Abbreviations: pHi, intracellular pH; cAMP, cyclic AMP; sAC, soluble adenylyl cyclase; $\mathrm{NHEs,} \mathrm{sodium}\left(\mathrm{Na}^{+}\right)$-hydrogen $\left(\mathrm{H}^{+}\right)$exchangers; $\mathrm{NHAs,} \mathrm{Na}^{+} / \mathrm{H}^{+}$antiporters; LHR, luteinizing hormone receptor; PKA, protein kinase $A ; s A C_{f f}$, full-length $S A C ; s A C_{t}$, truncated forms of $S A C ; P C R$, polymerase chain reaction; $C N B D$, cyclic nucleotide binding domain; ES, embryonic stem; H\&E, hematoxylin and eosin; PFA, paraformaldehyde; TEM, transmission electronic microscopy

Received 27.1.16; revised 20.2.16; accepted 25.2.16; Edited by M Agostini
} 
NHE, NHA1 (SLC9B1, also known as NHEDC1). Our subsequent study demonstrates that anti-NHA1 antibody reduced sperm motility and the rate of in vitro fertilization. ${ }^{23}$ Therefore, NHA1 is proposed to regulate sperm motility. The critical role for NHA1 in human male fertility is highlighted by the finding that $N H A 1$ expression is either reduced or absent in patients with teratozoospermia. ${ }^{24}$

In order to define the physiological function of NHA1 in spermatozoa, we generated Nha1 cKO, Nha2 cKO and Nha1/2 dKO male mice. Although single conditional knockouts for Nha1 or Nha2 were subfertile, male double knockout mice exhibited completely infertile with severely diminished sperm motility. cAMP synthesis by sAC was attenuated in cKO and dKO spermatozoa. Furthermore, the sperm motility defects could be rescued by the addition of cell-permeable cAMP analogs. In addition, the number of newborns and fertility rate of Nha1/2-vaccinated female mice were significantly stepped down, suggesting NHA1 and 2 may be an excellent target molecules for developing a novel male contraceptive.

\section{Results}

NHA1 and NHA2 expression in sperm. Our previous reports suggest that NHA1 is exclusively expressed in mouse testis. ${ }^{11,23}$ We further found that NHA1 was specifically localized to the sperm tail during late spermatogenesis (Figures $1 \mathrm{a}$ and $\mathrm{b}$ ) and sperm storage in cauda epididymis (Figures 1c and d). High-magnification immunofluorescence of isolated sperm from cauda epididymis further demonstrated that the localization of NHA1 was confined to the principal piece of flagella (Figures 1e and f). Nha1 seems most closely related to Nha2 (Figure $1 \mathrm{~g}$ ). We further found that NHA2 is specifically localized in the principal piece of sperm tail, which is similar to NHA1 expression pattern (Figures 1h-j).

Generation and analysis of Nha1 knockout mice. Our previous study suggests that polyclonal antibody to transmembrane region of $\mathrm{NHA} 1$ significantly reduced the in vitro sperm motility and fertilization. ${ }^{11}$ To elucidate the physiological function of NHA1, we generated Nha1 knockout mice by
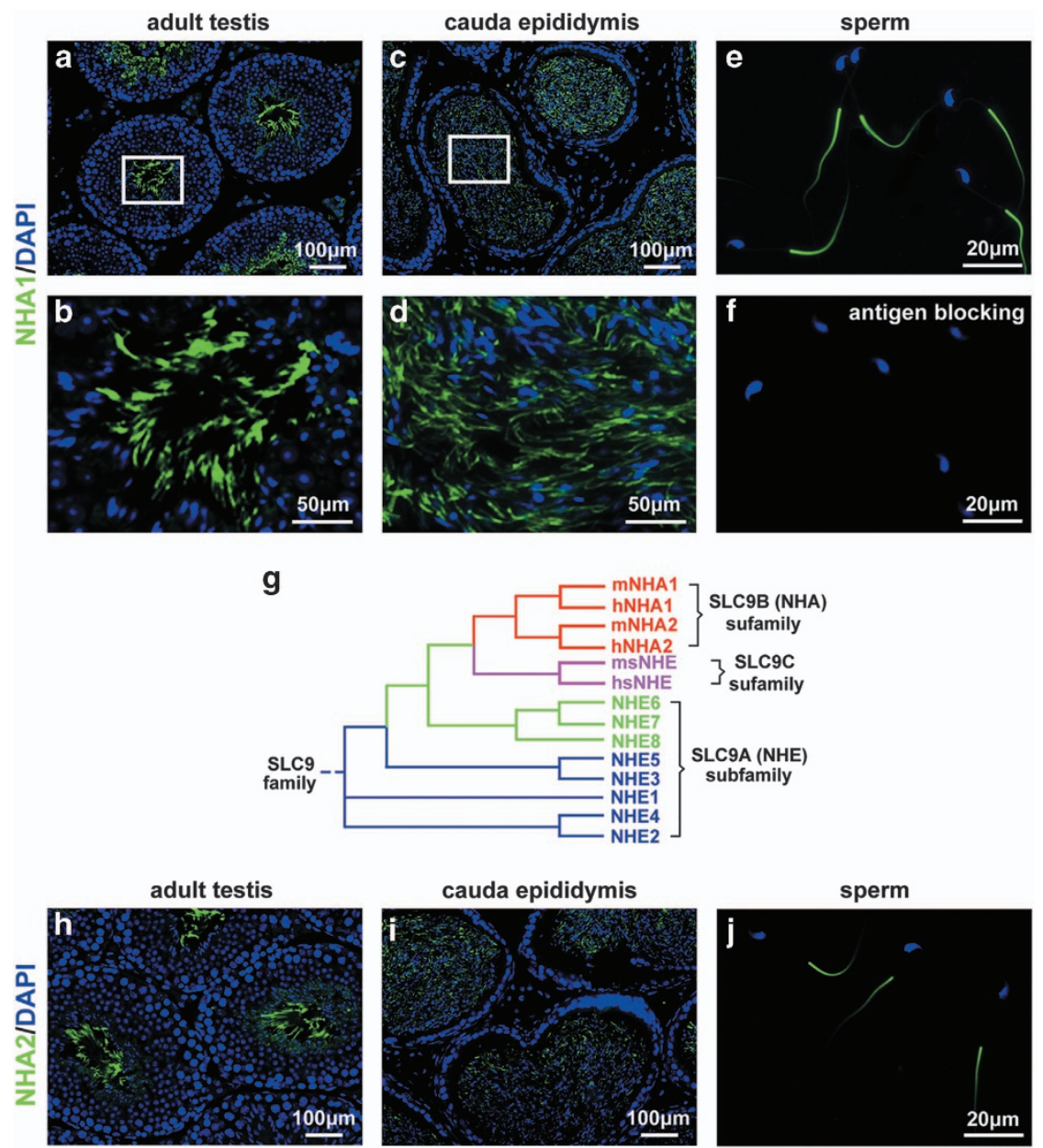

Figure 1 NHA1 and NHA2 were specifically expressed in the principal piece of sperm tail. (a-f) Immunofluorescence staining of NHA1 in mouse testis (a and $\mathbf{b}$ ), cauda epididymis ( $\mathbf{c}$ and $\mathbf{d}$ ) and sperm from cauda epididymis (e). Note the intensive green signal at principal piece of sperm tail. NHA1 antibody staining in the presence of competing immunogen (f). The nuclei are counterstained with DAPI (blue). (g) Phylogenetic tree displays the relationship between the NHA1 and the other NHEs. The tree was generated with GeneBee aligning the predicted open reading frames of each NHE. (h-j) Immunofluorescence staining of NHA2 in mouse testis (h), cauda epididymis (i) and sperm from cauda epididymis (j). Scale bar in a, c, h and $\mathbf{i}, 100 \mu \mathrm{m}$. Scale bar in $\mathbf{b}$ and $\mathbf{d}, 50 \mu \mathrm{m}$. Scale bar in $\mathbf{e}, \mathbf{f}$ and $\mathbf{j}, 20 \mu \mathrm{m}$ 

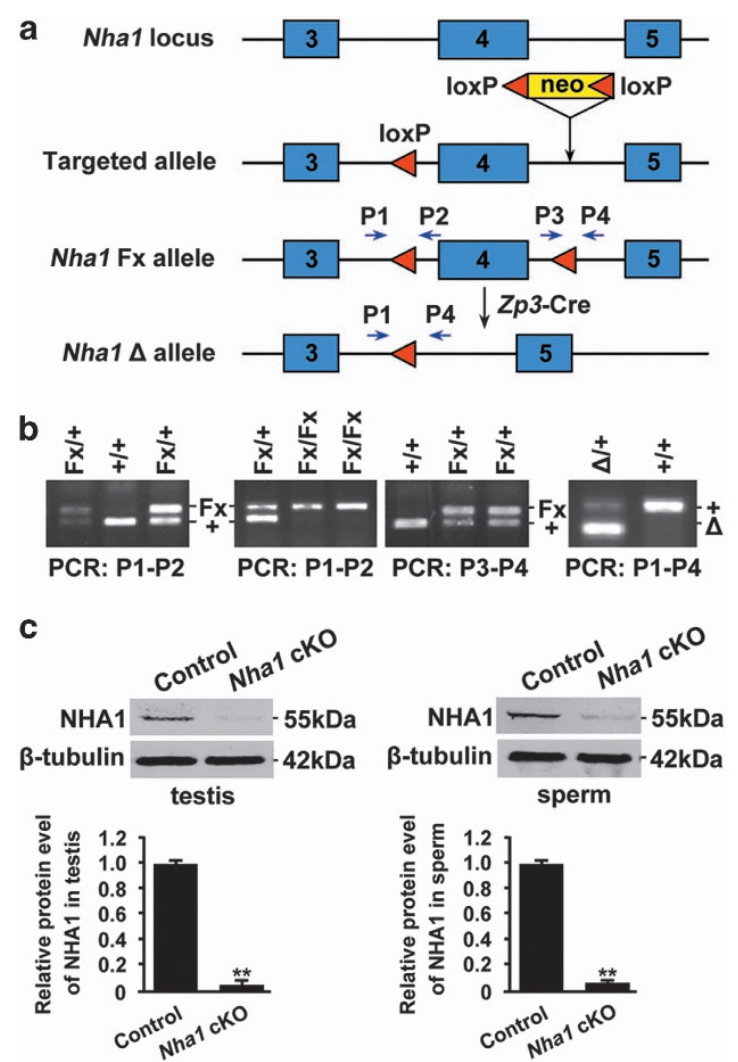

Figure 2 Diagram illustrates our targeting strategy and the creation of Nha1 cKO mice. (a) In the targeted allele, a loxP site and a pgk-neo cassette flanked by two loxP sites are inserted into intron 3 and intron 4, respectively. Mice carrying the Nha1targeted allele were crossed with the Cre transgenic mice to generate progeny carrying the Nha1Fx or Nha1 $\triangle$ allele. (b) PCR analysis detects the presence of 5' (PCR: P1-P2) and 3' (PCR: P3-P4) loxP sites for genotyping the wild-type (+/+), heterozygous $(\mathrm{Fx} /+)$ and homozygous ( $\mathrm{Fx} / \mathrm{Fx}$ ) mice, and examines the deletion of exon 4 in the Nha1 $\triangle /+$ mice (PCR: P1-P4). (c) The knockout efficiency was confirmed by western blotting in testis and sperm samples. The protein level was normalized and plotted against $\beta$-tubulin. The data are expressed as the mean \pm S.D. ${ }^{* *} P<0.01$

homologous recombination technology. LoxP sites flank exon 4 of the Nha1 allele, and recombination of the loxP sites using Cre recombinase resulted in the removal of exon 4 (Figure 2a). The successful acquisition of Nha1 cKO mice was determined by polymerase chain reaction (PCR) amplification (Figure 2b). We confirmed that NHA1 was successfully depleted in both testis and spermatozoa in Nha1 cKO males (Figure 2c).

In Nha1 cKO male mice, there were no overt abnormalities in testicular weight $(123 \pm 4 \mathrm{mg}$ in wild-type and $110 \pm 9 \mathrm{mg}$ in cKO), epididymal weight $(40 \pm 1 \mathrm{mg}$ in wild-type and $36 \pm 2 \mathrm{mg}$ in $\mathrm{CKO})$ and sperm count $\left(1.4 \pm 0.2 \times 10^{6} / \mathrm{ml}\right.$ in wild-type and $1.4 \pm 0.3 \times 10^{6} / \mathrm{ml}$ in cKO) (Figures 3a-c). No overt abnormalities in spermatogenesis and epididymis of Nha1 cKO mice (Figure 3d). Isolated sperm from cauda epididymis exhibited typical morphology (Figure 3d) and flagella structure (Figure 3e).

NHA1 is essential for sperm motility and male fertility. By breeding assay, we found that although Nha1 cKO males copulated, the pregnancy rate $(92 \%$ in wild-type and $52.5 \%$ in
cKO) and litter size $(11.5 \pm 0.3$ in wild-type and $5.2 \pm 0.4$ in $\mathrm{cKO}$ ) were markedly lower compared with their control littermates (Figures $4 a$ and b). Acrosome reaction, a prerequisite for spermatozoa to fertilize eggs, occurred normally in Nha1 cKO spermatozoa (acrosome rate: $58 \pm 1 \%$ in wild-type and $61 \pm 1 \%$ in $\mathrm{cKO}$ ) (Figure 4c). However, percentage motility of Nha1 cKO spermatozoa after release from the caudal epididymis was significantly lower than those of control spermatozoa ( $82 \pm 3 \%$ in wild-type and $38 \pm 2 \%$ in cKO) (Figure 4d). Moreover, fewer spermatozoa of Nha1 cKO males reached the female oviduct $4-6 \mathrm{~h}$ after coitus, compared with those of controls (Figures $4 e$ and f).

cAMP analogs rescue the motility defects of Nha1 cKO spermatozoa. Our previous study suggests that sperm $\mathrm{pHi}$ descends after treatment with the NHA1 antisera. ${ }^{11}$ Given that cAMP synthesis by $\mathrm{sAC}$ is closely related to sperm $\mathrm{pHi}$ regulation and sperm motility, we detected the levels of cAMP and SAC in Nha1 cKO spermatozoa. Basal cAMP concentrations were significantly lower in Nha1 cKO spermatozoa compared with wild-type sperm cells $\left(76 \pm 3 \mathrm{fmol} / 10^{6}\right.$ cells in wild-type and $34 \pm 2 \mathrm{fmol} / 10^{6}$ cells in cKO) (Figure $5 \mathrm{a}$ ). The protein level of $\mathrm{SAC}_{\mathrm{fl}}$, a cAMP synthetase, was greatly diminished in Nha1 cKO spermatozoa (Figure 5b). Moreover, transfection of $\mathrm{NHA1}$ enhanced $\mathrm{SAC}_{\mathrm{fl}}$ protein expression in HEK293F cells (Figure 5c). Notably, addition of membranepermeable cAMP analogs, such as Sp-cAMP, 8-Br-cAMP and AM-cAMP, almost fully recovered the sperm motility of Nha1 cKO sperm (Figure 5d).

Generation of Nha2 cKO and Nha1/2 dKO mice. Nucleotide sequence is very similar between Nha1 and Nha2, indicating two Nha genes may be functionally redundant. Accordingly, we generated Nha2 cKO and Nha1/2 dKO mice. LoxP sites flank exon 3 of the Nha2 allele, and recombination of the loxP sites using Cre recombinase resulted in the removal of exon 4 (Supplementary Figures S1a-c). Afterward, we generated Nha1/2 dKO mice (Supplementary Figure S1d).

Similar to Nha1 cKO, no overt abnormalities in testicular weight $(120 \pm 3 \mathrm{mg}$ in wild-type and $112 \pm 4 \mathrm{mg}$ in $\mathrm{cKO})$, epididymal weight $(38 \pm 1 \mathrm{mg}$ in wild-type and $36 \pm 2 \mathrm{mg}$ in cKO) and sperm count $\left(1.3 \pm 0.2 \times 10^{6} / \mathrm{ml}\right.$ in wild-type and $1.3 \pm 0.3 \times 10^{6} / \mathrm{ml}$ in $\left.\mathrm{cKO}\right)$, spermatogenesis, epididymis and epididymal sperm structure of Nha2 cKO males (Supplementary Figures S2a-f). The pregnancy rate $(91.6 \%$ in wild-type and $65 \%$ in cKO) and litter size (11.5 \pm 0.2 in wildtype and $7.2 \pm 0.3$ in cKO) of Nha2 cKO males were markedly lower compared with their control littermates (Supplementary Figures $\mathrm{S} 3 \mathrm{a}$ and $\mathrm{b})$. Nha2 deletion significantly reduced the percentage of motile sperm ( $84 \pm 2 \%$ in wild-type and $56 \pm 3 \%$ in cKO) (Supplementary Figure S3c) and the cAMP synthesis by SAC (Supplementary Figures S3d and e).

In addition, the mRNA level of Nha2 was significantly increased in the Nha1 cKO sperm (Supplementary Figure S4a). Similarly, significant upregulation of Nha1 level was observed after deletion of Nha2 (Supplementary Figure S4b). Collectively, these two Nha genes are functionally redundant. 

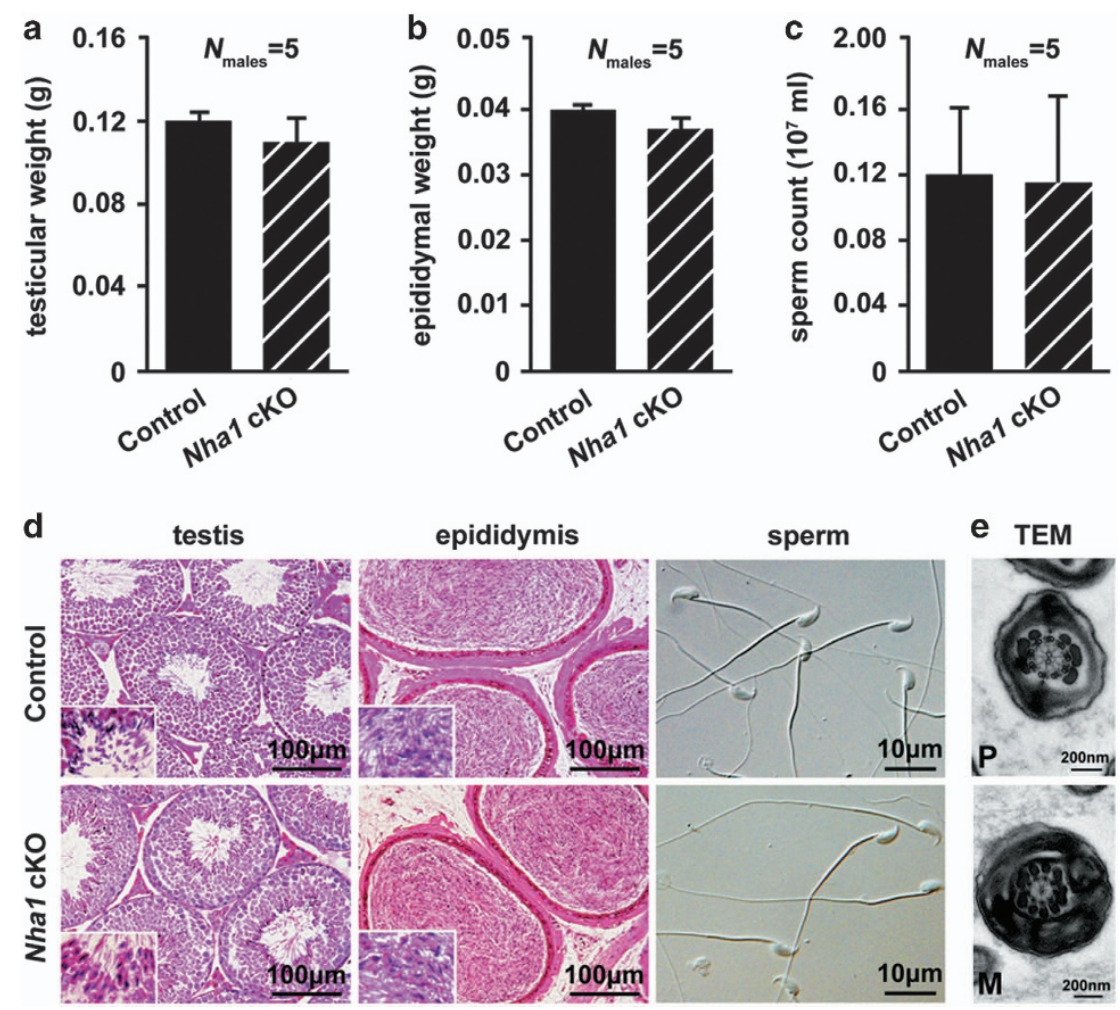

Figure 3 Testis and sperm morphology of Nha1 cKO mice. (a-c) Testicular weight (a), epididymal weight (b) and sperm count (c) were examined. No overt abnormalities were found in the Nha1 cKO mice. Data are expressed as the means \pm S.D. $(n=5)$. (d) Testicular and cauda epididymal sections stained with H\&E and spermatozoa obtained form cauda epididymis. No overt morphological abnormalities were observed in the testis or spermatozoa of Nha1 cKO mice. (e) Sperm principal piece ( $P$; upper panels) and midpiece (M; lower panels) were observed with TEM. No structural abnormalities were observed. Scale bar in d (the first two columns), $100 \mu \mathrm{m}$. Scale bar in d (third column), $10 \mu \mathrm{m}$. Scale bar in $\mathbf{e}, 200 \mathrm{~nm}$

Nha1/2 dKO males are infertile. No obvious behavioral and gross anatomical differences were noted when comparing adult Nha1/2 dKO males and wild-type littermates. Also, no relevant changes in testicular weight $(110 \pm 4 \mathrm{mg}$ in wild-type and $104 \pm 6 \mathrm{mg}$ in $\mathrm{dKO}$ ), epididymal weight ( $37 \pm 1 \mathrm{mg}$ in widtype and $36 \pm 2 \mathrm{mg}$ in dKO) and sperm count $\left(1.3 \pm 0.2 \times 10^{6} /\right.$ $\mathrm{ml}$ in wild-type and $1.2 \pm 0.2 \times 10^{6} / \mathrm{ml}$ in $\mathrm{dKO}$ ) were observed in Nha1/2 dKO males (Supplementary Figures S2g-i). Elongated spermatids were present in testes and spermatozoa were present in the epididymis (Supplementary Figures $\mathrm{S} 2 \mathrm{j}-\mathrm{k}$ ). Moreover, isolated sperm from cauda epididymis exhibited typical morphology (Supplementary Figure S2I).

Mating behavior of male Nha1/2 dKO mice was normal because vaginal plugs were observed in the females. However, mating of Nha1/2 dKO male mice with wild-type females for 2 months did not produce any pregnancies (Figure 6a). Motility analysis indicated that sperm motility was drastically reduced in Nha1/2 dKO males when compared with control littermates ( $84 \pm 2 \%$ in wild-type and $5 \pm 1 \%$ in $\mathrm{dKO}$ ) (Figure 6b). Nha1/2 dKO sperm produced only a slightly trembling movement of the flagella. Significant reduced levels of cAMP $\left(80 \pm 2 \mathrm{fmol} / 10^{6}\right.$ cells in wild-type and $17 \pm 2 \mathrm{fmol} / 10^{6}$ cells in $\mathrm{dKO})$ and $\mathrm{sAC}_{\mathrm{fl}}(<20$-fold) were observed in Nha1/2 dKO sperm cells (Figures $6 \mathrm{c}$ and $\mathrm{d}$ ).

Contraceptive function of pCR-Nha1/2 vaccine. Oral vaccination of female mice with $\mathrm{pCR}-$ Nha1/2 significantly reduced both the pregnancy rate $(90 \%$ in control and $13 \%$ in vaccinated group) and the number of newborns $(10.3 \pm 0.2$ in control and $3.2 \pm 0.2$ in vaccinated group), as compared with the pCR3.1 mock plasmid (Figures 6e and f). Sperm motility was statistically reduced when sperm were mixed with vaginal wash from the $\mathrm{pCR}-\mathrm{Nha1/2}$ orally vaccinated females ( $80 \pm 2 \%$ in control and $27 \pm 1 \%$ in vaccinated group) (Figure 6g). Notably, sperm agglutination was only observed as the cross-linking or clumping together when sperm were treated with vaginal wash from the pCR-Nha1/2-vaccinated female mice (Figure 6h).

Sperm distribution of NHA1 are present across mammalian species. To determine whether sperm distribution of NHA1 is phylogenetically conserved in spermatogenesis, we performed immunolocalization of NHA1 in testes or sperm from diverse mammalian species, including rat, monkey, goat, bull, mouse and human (Figure 6i). As expected, NHA1 was specifically localized to the sperm tail during late spermatogenesis and confined to the principal piece of flagella.

\section{Discussion}

Fertilization is a fundamental and convoluted process. However, we are still far from fully understanding the gamete intracellular molecular dialog necessary for fertilization. Furthermore, it is needed to tackle increasing male infertility and to provide safer male gamete-based contraceptives. 
a

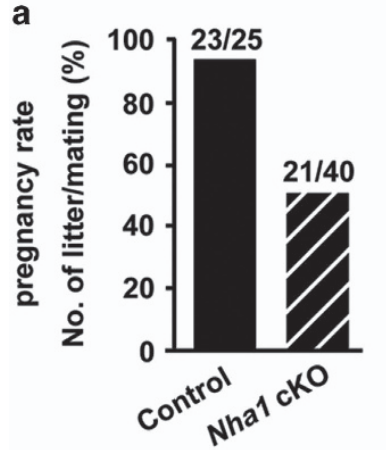

e

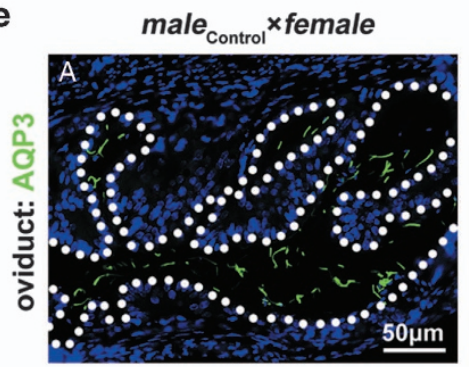

b

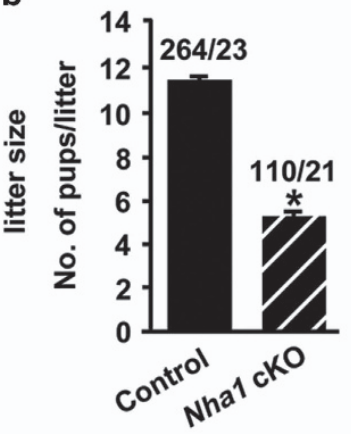

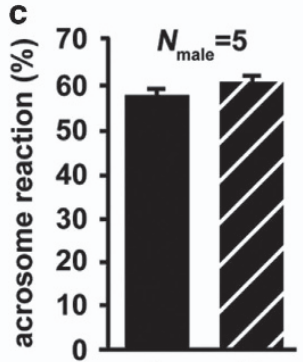

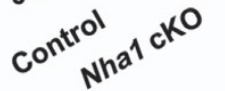

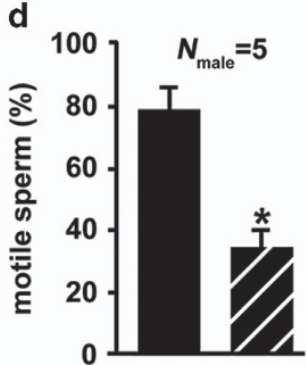

$\mathrm{CON}_{\mathrm{nhal}} \mathrm{CHO}$
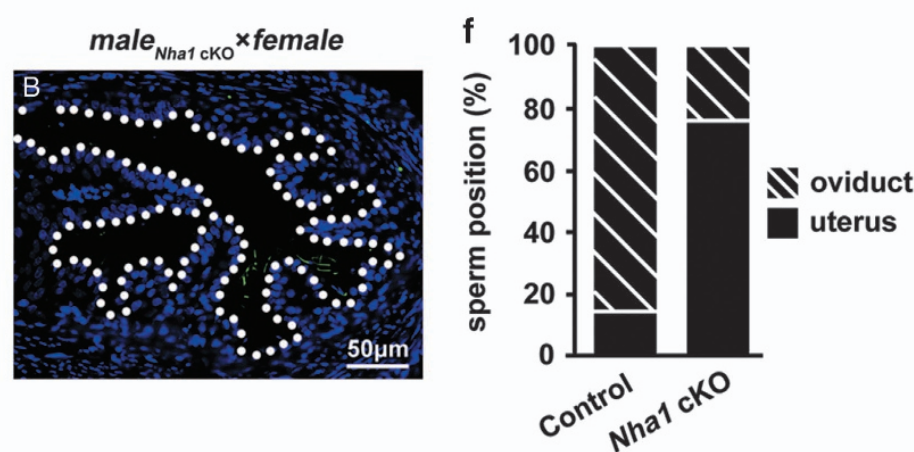

Figure 4 Nha1 cKO male mice are subfertile. (a) Pregnancy rate was calculated as the ratio of the number of females with pregnancy to the number of females with successful mating. (b) When calculating average litter size, only the females that generated pups were included. (c) The percentage of sperm that underwent acrosome reaction (AR) after A23187 induction was counted. (d) Percentage motility of Nha1 $\mathrm{cKO}$ and wild-type spermatozoa after release from the cauda epididymis. Data in a-d are expressed as the means \pm S.D., ${ }^{*} P<0.05$. (e) Oviduct was collected from females mated with Nha1 knockout and wild-type males $4-6 \mathrm{~h}$ after coitus. Sperm tails were staining with AQP3 antibody (green). The nuclei are counterstained with DAPI (blue). Note that Nha1 cKO sperm were seldomly observed in the oviduct. Scale bar in d, $50 \mu \mathrm{m}$. (f) The sperm position was calculated in uterus or oviduct of females mated with Nha1 cKO and wild-type males 4-6 $\mathrm{h}$ after coitus
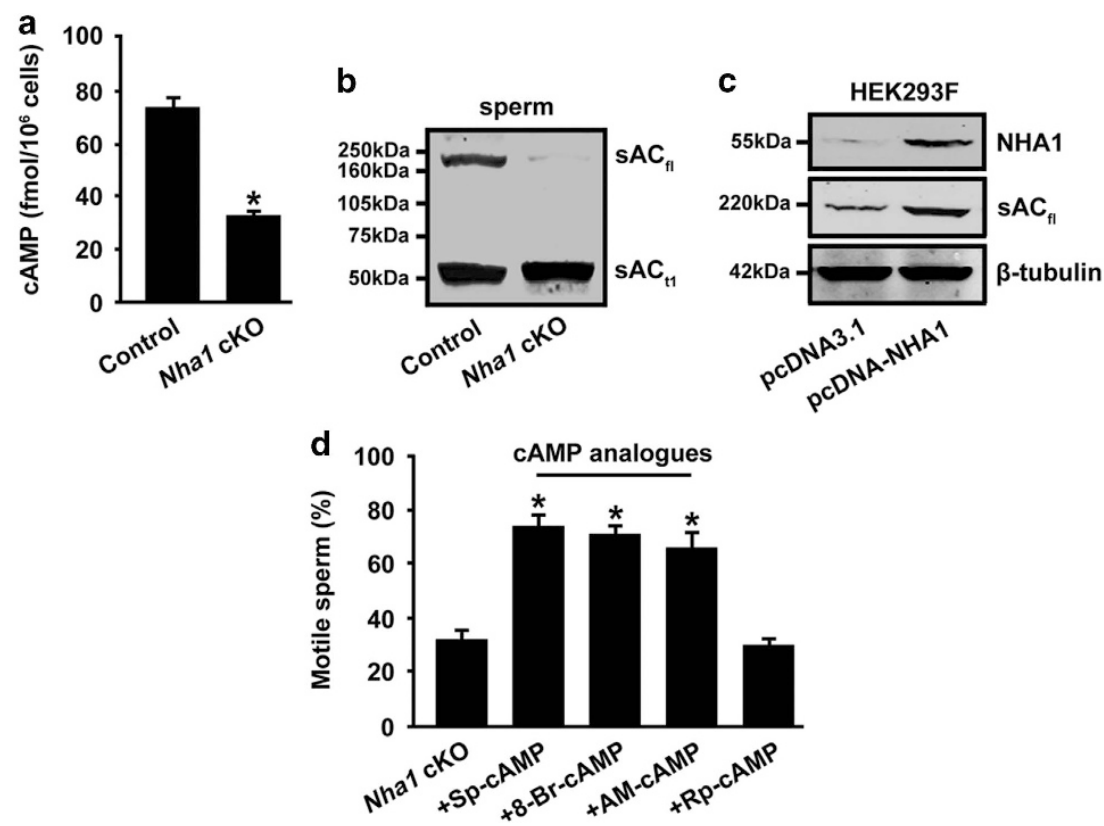

Figure 5 sAC-mediated cAMP signaling is compromised in Nha1 cKO spermatozoa. (a) Sperm from wild-type and Nha1 cKO mice were collected in a bicarbonate-free medium. cAMP content was measured by using RIA. Data represent the mean \pm S.D. $(n=3)$. (b) Percentage motility of null spermatozoa after a 60-min incubation with cAMP analogs plus $100 \mu \mathrm{M}$ IBMX. Sp-cAMP (1 mM); 8-Br-cAMP (1 mM); AM: AM-cAMP (50 $\mu \mathrm{M})$; Rp-cAMP is the biologically inactive cAMP analog (1 mM). Data in $\mathbf{a}$ and $\mathbf{b}$ are expressed as the means \pm S.D., ${ }^{*} P<0.05$. (c) Immunoblot of total sperm cell lysate $\left(2 \times 10^{6}\right.$ cells) from wild-type or Nha1 cKO mice with anti-sAC antibody, which detected two major proteins: a $\mathrm{SAC}_{\mathrm{fl}}$ and a truncated $\mathrm{SAC}\left(\mathrm{sAC}_{\mathrm{t} 1}\right)$. (d) HEK293F cells were trasfected with pcDNA-Nha1 or empty pcDNA3.1 vector. Total cell lysates were used for immunoblotting with anti-NHA1 or anti-sAC antibody. The protein level was normalized and plotted against $\beta$-tubulin 

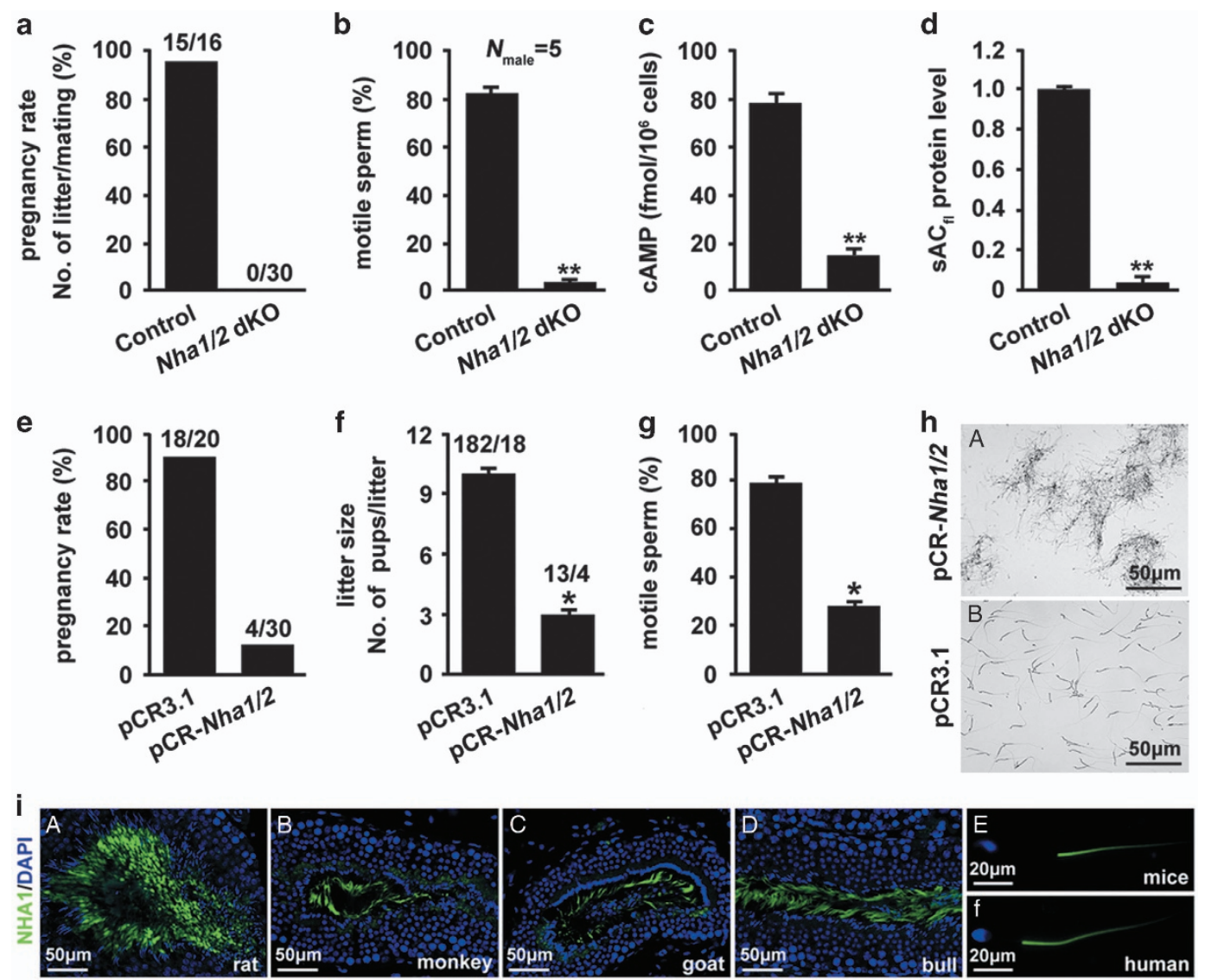

Figure 6 Nha1/2 dKO males are infertile and potential contraceptive role of pCR-Nha1/2 DNA vaccine. (a) Pregnancy rate is presented as a percentage. (b) Percentage motility of Nha1/2 dKO and wild-type spermatozoa after release from the caudal epididymis. (c) cAMP content of spermatozoa was measured by using RIA. (d) The protein level of $\mathrm{SAC}_{\mathrm{fl}}$ (normalized and plotted against $\beta$-tubulin) in Nha1/2 $\mathrm{dKO}$ and wild-type spermatozoa. (e and $\mathrm{f}$ ) The effect of the pCR-Nha1/2 DNA vaccine on pregnancy rate (e) and litter size were examined (f). (g) Spermatozoa motility treated with the vaginal fluid of pCR-Nha1/2 orally immunized mouse as compared with that of the pCR3.1 group. Data in a-g are expressed as the means \pm S.D., ${ }^{*} P<0.05 ;{ }^{* *} P<0.01$. (h) Sperm suspensions of normal mouse were mixed with vaginal fluid of $p C R-N h a 1 / 2$ or $p C R 3.1$ immunized females. Note that agglutination in a tangled pattern was only observed in pCR-Nha1/2 group. Scale bar, $50 \mu \mathrm{m}$. (i) Immunolocalization of NHA1 in tissue sections of testes or sperm sample from diverse mammalian species, including rat, monkey, goat, bull, mice and human. Scale bar in a-d, $50 \mu \mathrm{m}$. Scale bar in e and f, $10 \mu \mathrm{m}$

Pathological and pharmacological studies of the specific ion channel from spermatozoa, in the species where it can be done (i.e., null mice), will yield clear evidence of the role of the channel in sperm physiology and final fertilization. In this study, we showed that sodium-hydrogen exchangers, NHA1 and NHA2, were essential for sperm function as their elimination caused infertility in male mice because of a severe defect on sperm motility.

Several unique sperm ion transporters and enzymes whose elimination causes infertility are either $\mathrm{pHi}$ dependent or somehow related to $\mathrm{pHi}$ regulation. Among them are: CatSper, a Ca ${ }^{2+}$ channel; Slo3, a $\mathrm{K}^{+}$channel; $\mathrm{Na}^{+} / \mathrm{H}^{+}$exchanger and the SAC (reviewed in Nishigaki et al. ${ }^{4}$ ). An increase in bicarbonate $\left(\mathrm{HCO}_{3}^{-}\right)$during the transit from the epididymis to the female genital tract $\left(\mathrm{HCO}_{3}^{-}<1 \mathrm{mM}\right.$ in cauda epididymis, whereas $\mathrm{HCO}_{3}^{-}>10 \mathrm{mM}$ in female reproductive tract) activates sAC. ${ }^{19,20,25} \mathrm{HCO}_{3}^{-}$-induced CAMP synthesis by SAC stimulates PKA and promotes sperm maturation, motility and capacitation in the female genital tract. ${ }^{26-28}$ In addition to PKA, cAMP is able to bind and regulate other proteins containing cyclic nucleotide binding domain (CNBD) ${ }^{29}$ A CNBD protein known to be present in mouse sperm is a specific member of the mammalian NHE superfamily of $\mathrm{Na}^{+} / \mathrm{H}^{+}$exchangers, sNHE. ${ }^{10}$ Targeted deletion of $s$ Nhe gene results in infertility because of severely diminished sperm motility. Interestingly, sperm from $s$ Nhe null mice lack motility but either permeable cAMP analogs or $\mathrm{NH}_{4} \mathrm{Cl}$ rescues this phenotype. ${ }^{10}$ Later report from the same group showed that SNHE is necessary for the full-length expression of SAC suggesting that these two proteins form a protein complex involved in sperm $\mathrm{pHi}$ control. ${ }^{13}$ Thus, it is proposed that cAMP affects the sperm $\mathrm{pHi}$ by controlling the sNHE through its CNBD. ${ }^{30}$

The phenotype of Nha1 cKO, Nha2 cKO and Nha1/2 dKO male mice is somewhat similar with $s$ Nhe null males as follows. First, male (sub)infertility is caused by severely diminished sperm motility. Second, their cAMP synthesis by SAC is highly diminished. Third, addition of membranepermeable cAMP analogs almost fully recovered the sperm motility of null sperm. Quite distinct from NHA1 and NHA2, sNHE contains a consensus sequence for a putative CNBD near the $\mathrm{C}$ terminus, implying that sNHE function could be regulated by cyclic nucleotides. However, we did not observe any CNBD in the nucleotide sequences of Nha1 or Nha2 gene. 
Based on knockout evidence, together with previous in vitro studies, we can infer that NHA1 and NHA2 are functional $\mathrm{Na}^{+} / \mathrm{H}^{+}$exchangers, and thus, Nha1 and Nha2 deficiency causes sperm pHi reduction and immotility most likely via attenuating SAC-mediated CAMP synthesis. However, how $\mathrm{NHA} 1$ and $\mathrm{NHA} 2$ regulate $\mathrm{SAC}$ and the exact correlation between $\mathrm{pHi}$ and CAMP level are still unclear. Further experiments, such as proteomic analysis and co-immunoprecipitation, will be useful to reveal whether NHA1 and/or NHA2 are the $\mathrm{sAC}$-associated proteins.

Besides, the defect of the Nha1-null sperm is clinically related, because NHA1 expression is either reduced or absent in patients with teratozoospermia, a male infertility condition characterized by the presence of abnormally shaped sperm in the semen (microarray data; Pubmed: GDS2697/1555142_at/ $S L C 9 B 1)$. Understanding the mechanisms regulating the expression of NHA1 gene is also of great importance. A recent study by Kumar et al. ${ }^{24}$ identifies and characterizes regulator DNA elements in the 5' end of the human NHA1 gene and suggests that DNA methylation at these elements can regulate its expression.

Previous studies identify several genes, which could be served as the candidate contraceptive targets, given their sperm-specific expression and absolute requirement for fertility. ${ }^{10,31-33}$ We are currently suggesting that male mice lacking Nha1 and Nha2 genes, sperm $\mathrm{Na}^{+} / \mathrm{H}^{+}$exchangers, are infertile, with seriously reduced sperm motility owing to attenuated SAC-mediated CAMP synthesis. Our study not only unveils a genetic basis for the role of $\mathrm{Na}^{+} / \mathrm{H}^{+}$exchangers in sperm motility, but also provides an attractive contraceptive targets in humans. Given that NHA1 and NHA2 exhibit a high degree of homology among different species, Nha1/2 DNA vaccine may be a good strategy for developing an immunocontraceptive vaccine for human and animal use. As shown in this study, the number of newborns and fertility rate of Nha1/2vaccinated female mice were significantly stepped down. However, the contraceptive efficiency of orally delivered Nha1/2 DNA vaccine remains to be improved.

\section{Materials and Methods}

Ethics statement. All animal procedures were in accordance with the Animal Care and Use Committee (IACUC) of Institute of Zoology, Chinese Academy of Sciences.

Antibody production. We produced anti-NHA1 polyclonal antisera obtained from the immunized rabbits using the purified NHA1 recombinant protein according to our previous study. ${ }^{11}$ Briefly, the selected partial cDNA sequence (encoding 62 amino acids) of the NHA1 was inserted into pGEX-4T-1 (Invitrogen, Carlsbad, CA, USA). The primer pair for cloning was: forward/BamHI (5'-TTGGATCCCATGGATC TGGAGGACT-3') and reverse/Sall (5'-AAGTCGACGGCACATGCCAATGGTT-3'). The preparation of recombinant protein (GST plus NHA1 fragment) and immunization of rabbits were performed as describes. ${ }^{34}$ Six rabbits of each group were immunized and the antisera were harvested from arteriae carotis. We produced anti-NHA2 polyclonal antisera according to the above method. The primer pair for cloning (encoding 83 amino acids) of NHA2 was: forward/BamHI (5'-TTGGATCCATCTACAGTTTTTAACATC-3') and reverse/Sall (5'-AAGTCGACTT GT CAGTCCACCTCATGCCTG-3').

Generation of Nha1 and Nha2 knockout mouse model. A targeting vector containing Nha1 exon 4 or Nha2 exon 3 flanked by a loxP site and a loxPNeo cassette was constructed and introduced into mouse embryonic stem (ES) cells $(A B 1,129 / \mathrm{SvEv})$ by electroporation. Next, ES cell clones containing the targeted Nha1 or Nha2 construct were injected into C57BL/6 (B6) blastocysts to generate chimeras. The resultant male chimeras were identified by coat color and mated with wild-type females to obtain germline transmission. Tail biopsies of agouti-pigmented $\mathrm{F} 1$ animals were genotyped using a primer set specific to the neo cassette. Nhat $1^{+/ F x}$ mice were mated with mice carrying $\mathrm{Nha}^{+/ / F x}$ and $\mathrm{Zp} 3-\mathrm{Cre}$ transgene mice (Cre recombinase expressed in the developing oocyte and in each cell of the resulting embryos) ${ }^{35}$ to generate Nha1 knockout mice. We used similar mating strategy to obtain Nha2 knockout mice. The DNA isolated from tail biopsies was used for genotyping. The presence of the Fx allele and Cre transgene was determined by PCR amplification. Mice were genotyped by PCR analysis using primers (5'-CCAGCATTCTCACAAACC-3' and 5'-AGACTGAACAAGCGAGCC-3') to identify the loxP locus, primers ( $5^{\prime}$-TTTTCTCATTTTCCATTCAACTACA- $3^{\prime}$ and $5^{\prime}$-AGCCCTACAATCCAGCCTTCAGAG-3') to identify the exon 4 deleted locus for Nha1 targeting. Mice were genotyped by PCR analysis using primers ( $5^{\prime}$-TTTT GTA GGCTCTTTTGC-3' and 5'-CACAGGGGTTGAGTCATA-3') to identify the loxP locus, primers (5'-TCGGAAGA GGGATACGGAAGT-3' and 5'-ATTGGCCTGGATG AAAACGAG $-3^{\prime}$ ) to identify the exon 3 deleted locus for Nha2 targeting.

Breeding assays. Eight to 12 weeks Nha1 cKO $(n=10)$, Nha2 cKO $(n=5)$, Nha1/2 dKO $(n=5)$ males and their control littermates males ( $n=5$ each) were used for the breeding assay. Each male mouse was caged with two adult wild-type females (7-8 weeks) that were checked for vaginal plugs every morning. Once a vaginal plug was identified, another female was placed in the cage for another round of mating. The plugged female was separated and single caged, and the pregnancy results were recorded.

Sperm count and motility assays. The cauda epididymis from 3-monthold male mice were placed in $1 \mathrm{ml}$ modified HTF media and backflushing was used to obtain spermatozoa. ${ }^{36}$ Spermatozoa were incubated with DAPI $(1: 1000$, Sigma-Aldrich, St. Louis, MO, USA) for 2 min. Samples were placed in Leja counting chambers (Orange Medical, Rotterdam, The Netherlands), and sperm concentration was evaluated by using the IVOS sperm analyzer (Hamilton Thorne Bioscience, St. Louis, MO, USA). Cauda epididymal spermatozoa in the media were treated with or without $50 \mu \mathrm{M}$ to $1 \mathrm{mM}$ CAMP analogs, and $100 \mu \mathrm{M} \mathrm{IBMX}$ (all purchased from Selleck, Shanghai, China). Motility of knockout spermatozoa after a 0- to 60-min incubation were analyzed by computer-assisted sperm analysis using the IVOS sperm analyzer (Hamilton Thorne Bioscience) and the motility rate (\%) was measured.

Hematoxylin and eosin (H\&E) staining. Testes and cauda epididymis were fixed in Bouin's solution for $24 \mathrm{~h}$. Following dehydration through an ethanol series, the fixed testes were embedded in paraffin and then sectioned. Paraffin sections (5- $\mu$ m-thick) were stained with H\&E (Zhong Shan Technology, Beijing, China). Staining were examined under light microscopy (Nikon DS-Ri1, Tokyo, Japan).

Immunofluorescence on tissue sections and epididymal sperm. Testes, cauda epididymis and oviduct were fixed in $4 \%$ paraformaldehyde (PFA) for $24 \mathrm{~h}$, dehydrated and embedded in paraffin. The sections (5- $\mu \mathrm{m}$-thick) were deparaffinized and rehydrated; heat-induced antigen retrieval was performed in $10 \mathrm{mM}$ sodium citrate buffer. Mouse sperm were collected from cauda epididymides using the backflushing method, washed in PBS, fixed in 4\% PFA for 30 min at room temperature and air dried on poly-L-lysine-treated slides. Sections were blocked using a blocking buffer (5\% donkey serum, $0.3 \%$ Triton X-100 in PBS) and incubated with primary antibodies against NHA1 $(1: 200$, our laboratory) or NHA2 (1:200, our laboratory) or AQP3 $(1: 400$, kind gift from Dr. Qi Chen) overnight at $4^{\circ} \mathrm{C}$. Sections were washed and incubated with anti-rabbit FITC-conjugated secondary antibody ( $1: 200$, Jackson Immuno Research, West Grove, PA, USA) for $1 \mathrm{~h}$ and counterstained with DAPI. Images were captured using a fluorescence microscope (Nikon Eclipse 80i).

Western blotting. Western blot analysis was performed as described previously. ${ }^{37}$ Briefly, testes and sperm were lysed in a radioimmune precipitation assay lysis buffer. The proteins were electrophoresed under reducing conditions on $10 \%$ SDS-PAGE gels and transferred to nitrocellulose membranes. The blots were incubated with the primary antibody overnight at $4{ }^{\circ} \mathrm{C}$ and then with the secondary antibody (anti-rabbit Dye 800CW, LI-COR, St. Louis, MO, USA) for $1 \mathrm{~h}$ at room temperature. The specific signals and the corresponding band intensities were evaluated using an Odyssey Infrared Imaging system (Odyssey, Berlin, Germany). The protein level was normalized and plotted against $\beta$-tubulin. The following 
antibodies were used in this study: rabbit anti-NHA1 (1/2000, our laboratory), rabbit anti-NHA2 (1/2000, our laboratory), rabbit anti-sAC (1/2000, Abgent, Cambridge, UK, AP5862c) and rabbit anti- $\beta$-tubulin (1/3000, Abcam, Cambridge, UK, 6046).

Quantitative RT-PCR. RNA was extracted using Trizol (Invitrogen, Dallas, TX, USA) according to the manufacturer's protocol. RNA samples were subjected to reverse transcription using a PrimeScript RT Reagent Kit (Takara, Dalian, China). The reactions were run in triplicate in three independent experiments. The CT values for the samples were normalized to the corresponding Gapdh CT values, and relative expression levels were calculated using the $\triangle \Delta C T$ method. The primer pair for Nha1: forward (5'-TGAGCACGACGTAGAATCAAAC- $\left.3^{\prime}\right)$ and reverse (5'-CA GGATCTTTGGACATCTCAACA-3'). The primer pair for Nha2: forward (5'-GCGAG CCTTTCTGGTTCTG- $3^{\prime}$ ) and reverse (5'-CACCTCATGCCTGCTAGGA-3').

Immunization with Nha1/2 DNA vaccine. The purified PCR product was inserted into pCR3.1 (Invitrogen, San Diego, CA, USA) according to the manufacturer's instruction. The primer pair for cloning Nha1 is: forward/Hindll (5'-GGCGAAGCTTGTTATGGGAGTTTTTG-3') and reverse/EcoRI (5'-GCGGAA TTCTTAATGATGGAAGTTCGAG-3'). The primer pair for cloning Nha2 is: forward/ HindIII (5'-GGCGAAGCTTCATGGTTGTTCTTCTG-3') and reverse/EcoRI (5'-GCG GAATTCCAGAAATTTCTATGCTTC- ${ }^{\prime}$ ). The female mice were immunized with the plasmid DNAs purified by using Qiagen Endofree Mega (Qiagen, St. Louis, MO, USA). Female mice were immunized with $20 \mu \mathrm{g}$ of Nha1/2 vaccine or pCR3.1 mock plasmid dissolved in $30 \mu \mathrm{l}$ of saline via oral feeding. One week after the second immunization, two immunized groups (female mice) were paired with wild-type males for 3 month. They were checked daily for mating as evidenced by a vaginal plug. The number of female mice that gave birth was recorded.

Sperm agglutination assay. One week after the second immunization, vaginal washes were collected. Sperm suspension (diluted to $20 \times 10^{6} \mathrm{cell} / \mathrm{s} / \mathrm{ml}$ ) and vaginal fluid were mixed in a proportion of $3: 1(\mathrm{v} / \mathrm{v})$ in a microcentrifuge tube. After incubation at $37^{\circ} \mathrm{C}$ for $1 \mathrm{~h}, 50 \mu \mathrm{l}$ of the mixture was dropped on glass slides, and the sperm agglutination and motility were examined under light microscopy (Nikon DS-Ri1).

Acrosome reaction. The A23187-induced acrosome reaction was analyzed as previously reported. ${ }^{38}$ Briefly, sperm were collected from the upper portion of HTF medium, and the calcium ionophore A23187 (Sigma) was added (final concentration $10 \mu \mathrm{M}$ ) to induce the acrosome reaction. Fifteen minutes later, the sperm were spotted on a glass microscope slide, dried at room temperature and fixed with methanol for $30 \mathrm{~s}$. Intact acrosomes were stained with FITC-PNA, and the sperm nuclei were labeled with DAPI. Sperm that had undergone the acrosome reaction could not be labeled with FITC-PNA. More than 200 sperm were examined for all experimental conditions.

Transmission electronic microscopy (TEM). Cauda epididymis was collected from wild-type and Nha1 cKO mice and fixed overnight in $2.5 \%$ glutaraldehyde in $0.1 \mathrm{M}$ phosphate buffer $(\mathrm{pH} 7.4)$, to allow the release of sperm. The sperm were collected and subsequently fixed in $2.5 \%(\mathrm{w} / \mathrm{v})$ glutaraldehyde solution in phosphate buffer $\left(\mathrm{pH} \mathrm{7.4)}\right.$ at $4{ }^{\circ} \mathrm{C}$ for $3 \mathrm{~h}$. Then, the sperm were washed in phosphate buffer, collected on poly-L-lysine-coated glass coverslips, postfixed with $1.0 \%$ osmium tetroxide for $1 \mathrm{~h}$, dehydrated in a graded series of ethanol and embedded in EPON/Araldite resin. Thin sections were cut, mounted on 200-mesh grids, and stained with uranyl acetate and lead citrate. The samples were then examined with a JSM-6360 LV scanning electron microscope (JEOL, Tokyo, Japan).

cAMP RIA. Intracytoplasmic concentration of cAMP in sperm was determined using an RIA kit (Pasteur, Lyon, France), with ${ }^{125}$ I-labeled cAMP used as a tracer. Cauda epididymal spermatozoa $\left(2 \times 10^{6}\right.$ cells) were released at $37^{\circ} \mathrm{C}$. The samples were first deproteinized by $0.4 \mathrm{~N}$ perchloric acid and then neutralized with $4 \mathrm{M}$ potassic acetate for $24 \mathrm{~h}$ at $4{ }^{\circ} \mathrm{C}$ as described. ${ }^{39}$ Samples were then centrifuged at $800 \mathrm{~g}$ for $10 \mathrm{~min}$ at $4^{\circ} \mathrm{C}$. In all, $100 \mu \mathrm{l}$ of the supernatant was used for RIA performed, in duplicate, according to the manufacturer's directions.

Cell transfection. HEK293F cells were grown in DMEM/F12 supplemented with $10 \% \mathrm{FBS}$ at $37{ }^{\circ} \mathrm{C}$ with $5 \% \mathrm{CO}_{2}$. The cells were seeded at a density of approximately 50000 cells per well in 12-well plates $12 \mathrm{~h}$ before transfection. Cells were transfected with pcDNA-Nha1 plasmid or empty pcDNA3.1 vector (Invitrogen, USA) via Lipofectamine 2000 (Invitrogen, USA) according to the manufacturer's recommendations. The primer pair for pcDNA-Nha1 cloning is: forward (5'-TT TTAAAGTTCCCTGCTGAAACGTAAG- $\left.3^{\prime}\right)$ and reverse (5'-GGTGATGATGGC AAGCTTTTTAATGAT- $3^{\prime}$ ). Transiently transfected cells were harvested $48 \mathrm{~h}$ later for analysis.

Statistical analysis. Data are expressed as the means \pm S.D. Statistical analyses were performed via ANOVA followed by Duncan's multiple range test for pairwise comparisons. Data analyses were performed using the SPSS software (SPSS Inc., Chicago, IL, USA). ${ }^{*} P<0.05$; ${ }^{* *} P<0.01$.

\section{Conflict of Interest}

The authors declare no conflict of interest.

Acknowledgements. We appreciate Professor Gao Fei from State Key Laboratory of Stem Cell and Reproductive Biology, Institute of Zoology, Chinese Academy of Sciences for providing $\mathrm{NHA}^{\mathrm{FX} /+}$ and $\mathrm{NHA}^{\mathrm{FX} /+}$ mice. We also thank Dr. Chen Qi from School of Medicine, University of Nevada for providing AQP3 antibody. This work was supported by Major Research Plan "973" Project (2011CB944302 and 2012CB944702), National Technology Support Project (2012DAl131B08) and Natural Science Foundation of China (31171380, 31471352, 31501198 and 81270662$)$.

1. Skakkebaek NE, Jorgensen N, Main KM, Rajpert-De Meyts E, Leffers $\mathrm{H}$, Andersson AM et al. Is human fecundity declining? Int J Androl 2006; 29: 2-11.

2. Liu Y, Wang DK, Chen LM. The physiology of bicarbonate transporters in mammalian reproduction. Biol Reprod 2012; 86: 99.

3. Florman HM, Jungnickel MK, Sutton KA. Shedding light on sperm pHertility. Cell 2010; 140: 310-312.

4. Nishigaki T, Jose O, Gonzalez-Cota AL, Romero F, Trevino CL, Darszon A. Intracellular pH in sperm physiology. Biochem Biophys Res Commun 2014; 450: 1149-1158.

5. Garcia MA, Meizel S. Regulation of intracellular pH in capacitated human spermatozoa by a $\mathrm{Na}+/ \mathrm{H}+$ exchanger. Mol Reprod Dev 1999; 52: 189-195.

6. Donowitz M, Cha B, Zachos NC, Brett CL, Sharma A, Tse CM et al. NHERF family and NHE3 regulation. J Physiol 2005; 567: 3-11.

7. Martins AD, Bernardino RL, Neuhaus-Oliveira A, Sousa M, Sa R, Alves MG et al. Physiology of $n a+h+$ exchangers in the male reproductive tract: relevance for male fertility. Biol Reprod 2014; 91: 11.

8. Woo AL, James PF, Lingrel JB. Roles of the Na,K-ATPase alpha4 isoform and the $\mathrm{Na}+/ \mathrm{H}+$ exchanger in sperm motility. Mol Reprod Dev 2002; 62: 348-356.

9. Klanke CA, Su YR, Callen DF, Wang Z, Meneton P, Baird N et al. Molecular cloning and physical and genetic mapping of a novel human $\mathrm{Na}+/ \mathrm{H}+$ exchanger (NHE5/SLC9A5) to chromosome 16q22.1. Genomics 1995; 25: 615-622.

10. Wang D, King SM, Quill TA, Doolittle LK, Garbers DL. A new sperm-specific $\mathrm{Na}_{+} / \mathrm{H}_{+}$ exchanger required for sperm motility and fertility. Nat Cell Biol 2003; 5: 1117-1122.

11. Liu T, Huang JC, Zuo WL, Lu CL, Chen M, Zhang XS et al. A novel testis-specific $\mathrm{Na}+/ \mathrm{H}_{+}$ exchanger is involved in sperm motility and fertility. Front Biosci 2010; 2: 566-581.

12. Bell SM, Schreiner CM, Schultheis PJ, Miller ML, Evans RL, Vorhees CV et al. Targeted disruption of the murine Nhe1 locus induces ataxia, growth retardation, and seizures. Am J Physiol 1999; 276: C788-C795.

13. Wang D, Hu J, Bobulescu IA, Quill TA, McLeroy $P$, Moe OW et al. A sperm-specific $\mathrm{Na}+/ \mathrm{H}+$ exchanger (sNHE) is critical for expression and in vivo bicarbonate regulation of the soluble adenylyl cyclase (SAC). Proc Natl Acad Sci USA 2007; 104: 9325-9330.

14. Xu H, Chen H, Li J, Zhao Y, Ghishan FK. Disruption of NHE8 expression impairs Leydig cell function in the testes. Am J Physiol Cell Physiol 2015; 308: C330-C338.

15. Buffone MG, Wertheimer EV, Visconti PE, Krapf D. Central role of soluble adenylyl cyclase and cAMP in sperm physiology. Biochim Biophys Acta 2014; 1842: 2610-2620.

16. Buck J, Sinclair ML, Schapal L, Cann MJ, Levin LR. Cytosolic adenylyl cyclase defines a unique signaling molecule in mammals. Proc Natl Acad Sci USA 1999; 96: 79-84.

17. Chen Y, Cann MJ, Litvin TN, lourgenko V, Sinclair ML, Levin LR et al. Soluble adenylyl cyclase as an evolutionarily conserved bicarbonate sensor. Science 2000; 289: 625-628.

18. Jaiswal BS, Conti M. Identification and functional analysis of splice variants of the germ cell soluble adenylyl cyclase. J Biol Chem 2001; 276: 31698-31708.

19. Esposito G, Jaiswal BS, Xie F, Krajnc-Franken MA, Robben TJ, Strik AM et al. Mice deficient for soluble adenylyl cyclase are infertile because of a severe sperm-motility defect. Proc Natl Acad Sci USA 2004; 101: 2993-2998.

20. Hess KC, Jones BH, Marquez B, Chen Y, Ord TS, Kamenetsky M et al. The "soluble" adenylyl cyclase in sperm mediates multiple signaling events required for fertilization. Dev Cell 2005; 9: 249-259.

21. Demarco IA, Espinosa F, Edwards J, Sosnik J, De La Vega-Beltran JL, Hockensmith JW et al. Involvement of a $\mathrm{Na}+/ \mathrm{HCO}-3$ cotransporter in mouse sperm capacitation. J Biol Chem 2003; 278: $7001-7009$. 
22. Zeng $\mathrm{Y}$, Oberdorf $\mathrm{JA}$, Florman $\mathrm{HM}$. $\mathrm{pH}$ regulation in mouse sperm: identification of $\mathrm{Na}(+)-, \mathrm{Cl}(-)-$, and $\mathrm{HCO}(-)-$ dependent and arylaminobenzoate-dependent regulatory mechanisms and characterization of their roles in sperm capacitation. Dev Biol 1996; 173: 510-520.

23. Liu T, Huang JC, Lu CL, Yang JL, Hu ZY, Gao F et al. Immunization with a DNA vaccine of testis-specific sodium-hydrogen exchanger by oral feeding or nasal instillation reduces fertility in female mice. Fertil Steril 2010; 93: 1556-1566.

24. Kumar PL, James PF. Identification and characterization of methylation-dependent/ independent DNA regulatory elements in the human SLC9B1 gene. Gene 2015; 561: 235-248.

25. Xie F, Garcia MA, Carlson AE, Schuh SM, Babcock DF, Jaiswal BS et al. Soluble adenylyl cyclase (SAC) is indispensable for sperm function and fertilization. Dev Biol 2006; 296: 353-362.

26. Visconti PE, Moore GD, Bailey JL, Leclerc P, Connors SA, Pan D et al. Capacitation of mouse spermatozoa. II. Protein tyrosine phosphorylation and capacitation are regulated by a cAMP-dependent pathway. Development 1995; 121: 1139-1150.

27. Wennemuth G, Carlson AE, Harper AJ, Babcock DF. Bicarbonate actions on flagellar and Ca2+ -channel responses: initial events in sperm activation. Development 2003; 130: 1317-1326.

28. Krahling AM, Alvarez L, Debowski K, Van Q, Gunkel M, Irsen S et al. CRIS-a novel cAMPbinding protein controlling spermiogenesis and the development of flagellar bending. PLOS Genet 2013; 9: e1003960.

29. Berman HM, Ten Eyck LF, Goodsell DS, Haste NM, Kornev A, Taylor SS. The CAMP binding domain: an ancient signaling module. Proc Natl Acad Sci USA 2005; 102 : 45-50.

30. Lishko PV, Kirichok Y, Ren D, Navarro B, Chung JJ, Clapham DE. The control of male fertility by spermatozoan ion channels. Ann Rev Physiol 2012; 74: 453-475.

31. Matzuk MM, McKeown MR, Filippakopoulos P, Li Q, Ma L, Agno JE et al. Small-molecule inhibition of BRDT for male contraception. Cell 2012; 150: 673-684.

32. Miyata $H$, Satouh $Y$, Mashiko D, Muto M, Nozawa $K$, Shiba $K$ et al. Sperm calcineurin inhibition prevents mouse fertility with implications for male contraceptive. Science 2015; 350: $442-445$.
33. Yuan S, Stratton CJ, Bao J, Zheng H, Bhetwal BP, Yanagimachi R et al. Spata6 is required for normal assembly of the sperm connecting piece and tight head-tail conjunction. Proc Natl Acad Sci USA 2015; 112: E430-E439.

34. Hu YX, Guo JY, Shen L, Chen Y, Zhang ZC, Zhang YL. Get effective polyclonal antisera in one month. Cell Res 2002; 12: 157-160.

35. de Vries WN, Binns LT, Fancher KS, Dean J, Moore R, Kemler R et al. Expression of Cre recombinase in mouse oocytes: a means to study maternal effect genes. Genesis 2000; 26: $110-112$.

36. Singleton CL, Killian GJ. A study of phospholipase in albumin and its role in inducing the acrosome reaction of guinea pig spermatozoa in vitro. J Androl 1983; 4: 150-156.

37. Chen SR, Tang JX, Cheng JM, Li J, Jin C, Li XY et al. Loss of Gata4 in Sertoli cells impairs the spermatogonial stem cell niche and causes germ cell exhaustion by attenuating chemokine signaling. Oncotarget 2015; 6: 37012-37027.

38. Hao J, Chen M, Ji S, Wang X, Wang Y, Huang X et al. Equatorin is not essential for acrosome biogenesis but is required for the acrosome reaction. Biochem Biophys Res Commun 2014; 444: $537-542$.

39. Fenichel P, Gharib A, Emiliozzi C, Donzeau M, Menezo Y. Stimulation of human sperm during capacitation in vitro by an adenosine agonist with specificity for A2 receptors. Biol Reprod 1996; 54: 1405-1411.

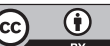

Cell Death and Disease is an open-access journal published by Nature Publishing Group. This work is licensed under a Creative Commons Attribution 4.0 International License. The images or other third party material in this article are included in the article's Creative Commons license, unless indicated otherwise in the credit line; if the material is not included under the Creative Commons license, users will need to obtain permission from the license holder to reproduce the material. To view a copy of this license, visit http://creativecommons.org/licenses/by/4.0/

Supplementary Information accompanies this paper on Cell Death and Disease website (http://www.nature.com/cddis) 